\title{
Genetic linkage and male homosexual orientation
}

\author{
Reasons to be cautious
}

The claim that male homosexuality is linked to chromosome $\mathrm{Xq} 28^{1}$ has enlivened the debate over nature versus nurture in human sexual orientation. When viewed against other genetic and epidemiological data and the complexities of linkage studies generally, however, the results invite further scrutiny.

Traditionally, linkage studies of behavioural traits are preceded by family, twin, and adoption studies. When characteristics seem to cluster in families twin, and especially adoption, studies are used to distinguish the influence of genetics from that of rearing. When concordance rates in monozygotic twins are higher than those in dizygotic twins this is taken as evidence for a genetic component. Adoption studies focus on phenotype rates in biological and adoptive parents of index cases versus controls; higher rates among biological relatives suggest that genetic factors are at play.

Twin studies of male homosexuality abound. Some show similar concordance in monozygotic and dizygotic twins whereas others suggest higher concordance in the monozygotic group. Most of these results are uninterpretable because of small samples or unresolved questions about phenotypic classification, the selection of cases, and the diagnosis of twin zygosity or because they make the untested assumption that monozygotic and dizygotic twins have similar environmental experiences such that any difference in concordance rate would be genetic in origin. ${ }^{23}$ Moreover, the finding that the adoptive brothers of homosexual twins are more prone to homosexuality than the biological siblings ${ }^{4}$ suggests that male homosexuality may well be environmental. Definitive twin and adoption studies of male homosexuality have yet to be done.

Support for a genetic hypothesis is further complicated by cultural and evolutionary considerations. Some culturesfor example, the Assyrian and Graeco-Roman-were very tolerant of homosexuality. The behaviour was practised openly and was highly prevalent. ${ }^{5}$ Sexual patterns are to some extent a product of society's expectations, but it would be difficult to envisage a change in the prevalence of a genetic trait merely in response to changing cultural norms. Also, from an evolutionary perspective, genetically determined homosexuality would have become extinct long ago because of reduced reproduction.

Thus the purported linkage stands in apparent contradiction to the flimsy genetic and epidemiological evidence. Two scenarios are possible. Firstly, despite the lack of supporting evidence, a substantial genetic factor does exist, and this is what the linkage result shows. Alternatively, the linkage reported is a false positive finding. To determine the most likely scenario we must consider the segregation patterns within the pedigrees studied by Hamer et al, the location of the supposed gene, and lessons from other studies of similarly complex traits.

A hallmark of $\mathrm{X}$ linked inheritance is maternal transmission. Indeed, as a prelude to their linkage study Hamer et al determined that in 76 random families maternal uncles and the sons of maternal aunts were the only groups of relatives with significantly higher rates of homosexual orientation than the rates in the general population. ${ }^{1}$ None of the probands' fathers were themselves homosexual. At face value these observations strongly support sex linked transmission. Nevertheless, a single gene or a particular genetic mechanism is unlikely to explain most of the variance in a phenomenon as complex as sexual orientation. Whether or not this sample is truly representative of familial homosexuality is an open question.

The families analysed for $\mathrm{X}$ linkage were recruited from a different population pool. ${ }^{1}$ Only the parents and brothers of selected male homosexual probands were examined for sexual orientation. As no systematic effort was made to exclude paternal transmission through more distant relatives (or at least to consider bilineal inheritance) the linkage results are ambiguous. Also, if we are to be confident of $\mathrm{X}$ linked transmission, families examined for $\mathrm{X}$ linkage must show absence of the presumed $\mathrm{X}$ linked trait in sons of affected men. Families with few opportunities for male to male inheritance are less compelling than those with many such opportunities. ${ }^{6}$ In the case of male homosexuality it is difficult to carry out such a study owing to diminished reproduction among male homosexuals. This problem can be circumvented by studying the offspring of heterosexual siblings, some of whom are probably carriers of the presumed susceptibility gene, but no data were provided on the offspring of male siblings in these families.

In their original analysis Hamer et al placed the homosexuality gene 8 centimorgans distal to the most telomeric marker. ${ }^{1}$ The short physical distance between this marker and the telomere, ${ }^{7}$ however, renders this result questionable. Since estimates of map location for complex traits may be biased (inflated), the investigators reanalysed their data by increasing both the penetrance of the non-trait associated allele (equivalent to increasing the proportion of phenocopies) and the frequency of the trait associated allele (equivalent to 
increasing the population prevalence of the trait). Indeed, this resulted in a more proximal location for the putative gene. The trade off, however, was a prevalence in the general population similar to the familial rates in the sample overall. In other words, the evidence for familial aggregation, the cornerstone of a genetic hypothesis, was attenuated.

There are lessons too from other studies-for example, of the hypothesis that another behavioural trait, manic depressive illness, is X linked. Support for this hypothesis was initially furnished by segregation patterns consistent with $\mathrm{X}$ linked transmission and reports of linkage to chromosomal region $\mathrm{Xq} 27-28$. In some studies the statistical support for these findings far exceeded the significance levels reported by Hamer et al. ${ }^{1}$ Moreover, the evidence from twin and adoption studies for a genetic component in manic depressive illness was far more compelling than that for homosexuality. Unfortunately, non-replication of the linkage findings by other investigators, as well as extension and reevaluation of the original data, has resulted in diminished support for this hypothesis. ${ }^{8}$ This outcome underscores the uncertainties in linkage studies of complex behavioural traits.

The claim of linkage of male homosexuality to chromosome Xq28 has wide social and political implications. Yet the scientific question is a complex one, and the interpretation of these results is hampered by methodological uncertainties. Further study is crucial to confirm or refute this finding.

Supported by a research scientist award MH00176 from the US Public Health Service-National Institute of Mental Health.

MIRON BARON Professor

Department of Psychiatry,

Columbia University College of Physicians and Surgeons,

Department of Medical Genetics,

New York State Psychiatric Institute,

New York, NY 10032, USA

1 Hamer DH, Hu S, Magnuson VL, Hu N, Pattatucci AML. A linkage between DNA markers on the $\mathrm{X}$ chromosome and male sexual orientation. Science 1993; 261:321-7.

2 Baron M. Genetics and human sexual orientation. Biol Psychiatry (in press).

3 Byne W, Parsons B. Human sexual orientation. The biologic theories reappraised. Arch Gen Psychiatry 1993;50:228-39.

4 Bailey JM, Pillard RC. A genetic study of male sexual orientation. Arch Gen Psychiatry 1991;48: 1089-96.

5 Wortis J. Homosexual warriors. Biol Psychiorry 1993;33:225-6.

6 Hebebrand J. A critical appraisal of X-linked bipolar illness. Br f Psychiatry 1992;160:7-11.

7 Davies KE, Mandel J-L, Monaco AP, Nussbaum RL, Willard HF. Report of the committee on the Davies KE, Mandel J-L, Monaco AP, Nussbaum RL, Willard HF. Report of the
genetic constitution of the X chromosome. Cytogenet Cell Genet 1991;58:853-966.

8 Baron $M$. Is there a gene for manic-depressive illness on the long arm of the X-chromosome? In: Gershon ES, Cloninger CR, eds. New genetic approaches to mental disorders. Washington, DC: American Psychiatric Press (in press).

\section{Service implications of the Calman report}

\section{Consultants' clinical responsibility is not negotiable; administrative structures are}

The Calman report ${ }^{1}$ has received a cautious welcome as a thoughtful attempt to harmonise European Community directives with the needs of higher specialist training in the United Kingdom. ${ }^{2}$ But the report is not just another interesting set of proposals to be debated and then discarded. Because the recommendations are driven by the requirements of European Community directives they seem likely to be implemented. They are therefore big news for junior doctors. They will, however, affect consultants even more than juniors. The Calman report opens the door to a consultant led hospital service, in which consultants deliver the bulk of medical care. In developing such a service it is important to distinguish what is and is not negotiable about the consultant's role.

After Calman it is expected that there will be many fewer registrars (the new higher specialist training grade), that each will spend less time on service work, and that, thanks to the new deal, ${ }^{3}$ they will be on call for no more than 72 hours a week. Doctors currently at registrar and senior registrar level will be replaced by an increased number of consultants. What emerges is a basic two tier hospital medical service, with consultants second on call to senior house officers (with or without preregistration house officers) and experienced trainees available only irregularly. In effect registrars will become supernumerary.

Some specialties already run essentially on this basis-in district general hospitals, for provision of elective care, in specialties with little contact with patients, and in the private sector. But the loss of the intermediate tier of junior doctors will have a profound effect on acute specialties which deal with emergencies around the clock and on university hospital units. It will be up to consultants to fill the hole created in service work and 24 hour cover by the departure of registrars. Although the blow may be cushioned to some extent by reallocation of inappropriate tasks, by the subconsultant career grades, and by foreign graduates in visiting posts, the general effect on consultant practice is likely to be profound.

Post Calman consultants would usually be appointed younger, probably at lower starting salaries, and would provide more of the bread and butter care for their patients (just as they might in private practice). What are the advantages? Emergencies would usually be treated by fully trained specialists rather than inexperienced juniors; inpatients would see their consultants on most days; consultants would perform the bulk of operations and procedures; new outpatients would be routinely evaluated by a consultant; and outpatients attending long term would see the same doctor on each visit. All these changes would be popular with the public and general practitioners and therefore with provider units keen to attract purchasers.

The nature of consultants' work would be transformed and their responsibility for out of hours cover would increase. Instead of very long working hours during training being followed by a relatively high degree of protection as a consultant, antisocial hours would thus be more evenly spread across a hospital doctor's career. In making this happen we must be careful not simply to shift long hours from juniors to seniors. The debate on juniors' hours has taught us that humane medical practice is predicated on humane conditions of service. It is clearly unreasonable to expect consultants to do more than their juniors, and the capacity to cope with long hours usually declines through middle age. New practices, including shifts, handovers, and team working, will need to be developed, and these can draw on the experience derived from implementing the new deal. An expanded consultant grade would also have to incorporate the expectation of professional development, with a changing pattern of salary, conditions, and responsibilities at different stages from appointment to retirement.

Such changes may appear to strike at the very foundations of consultant practice, so it is important to consider the 